\title{
Outcomes in patients with and without disability admitted to hospital with COVID-19: a retrospective cohort study
}

\author{
Hilary K. Brown PhD, Sudipta Saha SM, Timothy C.Y. Chan PhD, Angela M. Cheung MD PhD, \\ Michael Fralick MD PhD, Marzyeh Ghassemi PhD, Margaret Herridge MD MSc, Janice Kwan MD MPH, \\ Shail Rawal MD MPH, Laura Rosella PhD, Terence Tang MD, Adina Weinerman MD, Yona Lunsky PhD CPsych, \\ Fahad Razak MD MSc, Amol A. Verma MD MPhil
}

Cite as: CMAJ 2022 January 31;194:E112-21. doi: 10.1503/cmaj.211277

\begin{abstract}
Background: Disability-related considerations have largely been absent from the COVID-19 response, despite evidence that people with disabilities are at elevated risk for acquiring COVID-19. We evaluated clinical outcomes in- patients who were admitted to hospital with COVID-19 with a disability compared with patients without a disability.
\end{abstract}

Methods: We conducted a retrospective cohort study that included adults with COVID-19 who were admitted to hospital and discharged between Jan. 1, 2020, and Nov. 30, 2020, at 7 hospitals in Ontario, Canada. We compared in-hospital death, admission to the intensive care unit (ICU), hospital length of stay and unplanned 30-day readmission among patients with and without a physical disability, hearing or vision impairment, traumatic brain injury, or intellectual or developmental disability, overall and stratified by age ( $\leq 64$ and $\geq 65 \mathrm{yr}$ ) using multivariable regression, controlling for sex, residence in a long-term care facility and comorbidity.

Results: Among 1279 admissions to hospital for COVID-19, 22.3\% had a disability. We found that patients with a disability were more likely to die than those without a disability $(28.1 \%$ v. $17.6 \%)$, had longer hospital stays (median 13.9 v. $7.8 \mathrm{~d}$ ) and more readmissions ( $17.6 \%$ v. $7.9 \%$ ), but had lower ICU admission rates (22.5\% v. $28.3 \%$ ). After adjustment, there were no statistically significant differences between those with and without disabilities for in-hospital death or admission to ICU. After adjustment, patients with a disability had longer hospital stays (rate ratio $1.36,95 \%$ confidence interval $[\mathrm{Cl}]$ 1.19-1.56) and greater risk of readmission (relative risk $1.77,95 \% \mathrm{Cl} 1.14-$ 2.75). In age-stratified analyses, we observed longer hospital stays among patients with a disability than in those without, in both younger and older subgroups; readmission risk was driven by younger patients with a disability.

Interpretation: Patients with a disability who were admitted to hospital with COVID-19 had longer stays and elevated readmission risk than those without disabilities. Disability-related needs should be addressed to support these patients in hospital and after discharge.
A successful public health response to the COVID-19 pandemic requires accurate and timely identification of, and support for, high-risk groups. There is increasing recognition that marginalized groups, including congregate care residents, racial and ethnic minorities, and people experiencing poverty, have elevated incidence of COVID-19. ${ }^{1,2}$ Older age and comorbidities such as diabetes are also risk factors for severe COVID-19 outcomes. ${ }^{3,4}$ One potential high-risk group that has received relatively little attention is people with disabilities.

The World Health Organization estimates there are 1 billion people with disabilities globally. ${ }^{5}$ In North America, the prevalence of disability is $20 \%$, with one-third of people older than 65 years having a disability. ${ }^{6}$ Disabilities include physical disabilities, hearing and vision impairments, traumatic brain injury and intellectual or developmental disabilities. ${ }^{5,6}$ Although activity limitations experienced by people with disabilities are heterogeneous, ${ }^{5,6}$ people with disabilities share high rates of risk factors for acquiring COVID-19, including poverty, residence in congregate care and being members of racialized communities. ${ }^{7-9}$ People with disabilities may be more reliant on close contact with others to meet their daily needs, and some people with disabilities, especially intellectual developmental disabilities, may have difficulty following public 
health rules. Once they acquire SARS-CoV-2 infection, people with disabilities may be at risk for severe outcomes because they have elevated rates of comorbidities. ${ }^{10}$ Some disabilities (e.g., spinal cord injuries and neurologic disabilities) result in physiologic changes that increase vulnerability to respiratory diseases and may mask symptoms of acute respiratory disease, which may delay diagnosis. ${ }^{11-13}$ There have also been reports of barriers to high-quality hospital care for patients with disabilities who have COVID-19, including communication issues caused by the use of masks and restricted access to support persons. ${ }^{14-17}$

Some studies have suggested that patients with disabilities and COVID-19 are at elevated risk for severe disease and death, with most evaluating intellectual or developmental disability. ${ }^{13,18-26}$ Yet, consideration of disability-related needs has largely been absent from the COVID-19 response, with vaccine eligibility driven primarily by age and medical comorbidity, limited accommodations made for patients with disabilities who are in hospital, and disability data often not being captured in surveillance programs. ${ }^{14-17}$ To inform equitable pandemic supports, there is a need for data on patients with a broad range of disabilities who have COVID-19. We sought to evaluate standard clinical outcomes in patients admitted to hospital with COVID-1927 (i.e., inhospital death, intensive care unit [ICU] admission, hospital length of stay and unplanned 30-d readmission) for patients with and without a disability, overall and stratified by age. We hypothesized that patients with a disability would have worse outcomes because of a greater prevalence of comorbidities, ${ }^{10}$ physiologic characteristics that increase morbidity risk ${ }^{11-13}$ and barriers to high-quality hospital care. ${ }^{14-17}$

\section{Methods}

\section{Study design and data sources}

We conducted a retrospective cohort study using data from 5 academic and 2 community-based teaching hospitals in Toronto and Mississauga, Ontario, Canada, that are part of GEMINI, a hospital research collaborative. ${ }^{28}$ Data were collected from clinical and administrative information systems by GEMINI. ${ }^{29}$ Key data elements have $98 \%-100 \%$ accuracy compared with medical record review done manually. ${ }^{29}$ Data included demographics, diagnoses, vital signs, laboratory test results and use of hospital resources.

\section{Study population}

We included adults 18 years of age or older with COVID-19 who were admitted to an inpatient medical service (e.g., general medicine or respirology) or medical-surgical ICU and discharged between Jan. 1 and Nov. 30, 2020 (at 3 of the hospitals, data were available only from Jan. 1 to July 31, 2020). We identified COVID-19 diagnoses using International Statistical Classification of Diseases and Related Health Problems, 10th revision (ICD-10-CA) codes U07.1 and U07.2, ${ }^{27,30}$ with U07.1 having $98 \%$ sensitivity, $99 \%$ specificity and 92\% positive predictive value for COVID-19 detection compared with results for polymerase chain reaction (PCR) tests. ${ }^{31}$

We identified a disability using published algorithms to ascertain physical disability, ${ }^{32}$ hearing and vision impairments, ${ }^{33,34}$ traumatic brain injury ${ }^{35}$ and intellectual or developmental disability $^{36,37}$ in administrative data (Table 1). These algorithms include diagnoses associated with need for accommodations when accessing health care, ${ }^{32}$ functional limitations ${ }^{37,38}$ and adverse health outcomes. ${ }^{39}$ Other similar algorithms have shown a specificity of $100 \%$ and positive predictive value of $80 \%$ compared with data from disability service providers. ${ }^{40} \mathrm{We}$ considered dementia and psychiatric disorders as comorbidities rather than including them as part of the "disability" definition because both are strong risk factors for death from COVID-1941,42 and are common in some groups with disability. ${ }^{43,44}$ We considered disability to be present if 1 or more disability diagnoses were recorded in the index hospital admission or any previous admission to a general medicine service at 1 of the GEMINI hospitals after Apr. 1, 2010 (the beginning of the GEMINI database; before 2019, GEMINI collected data only on general medicine admissions).

\section{Outcomes}

We chose outcomes that were standard clinical indicators of severe COVID-19 outcomes among patients admitted to hospital: in-hospital death, ICU admission, total length of hospital stay and unplanned readmission to a medical service or medical-surgical ICU at any GEMINI hospital within 30 days of discharge but excluding interfacility transfers. ${ }^{27}$ We considered readmissions to be unplanned if they occurred through an emergency department.

\section{Covariates}

We measured age, sex, transfer from an acute care hospital, longterm care facility residence and comorbidity, which we ascertained through specific conditions (i.e., chronic obstructive pulmonary disease, coronary artery disease, dementia, diabetes mellitus, heart failure, hypertension and psychiatric disorders) using the Clinical Classification Software Refined (Agency for Healthcare Research and Quality) ${ }^{45}$ and via the Charlson Comorbidity Index. ${ }^{46}$ We used postal codes to ascertain neighbourhoodlevel income and visible minority quintiles (Postal Code ${ }^{\mathrm{OM}}$ Conversion File Plus, Statistics Canada; www150.statcan.gc.ca/n1/en/ catalogue/82F0086X). ${ }^{47}$ We ascertained vital signs, laboratory test results and mortality prediction scores at admission (modified Acute Physiology and Chronic Health Evaluation $[\mathrm{mAPACHE}]^{48}$ and ISARIC Coronavirus Clinical Characterisation Consortium 4C [ISARIC-4C] ${ }^{49}$ ).

\section{Statistical analysis}

We reported baseline characteristics, vital signs, laboratory test results and mortality prediction scores at admission of patients admitted to hospital with COVID-19 with and without a disability using descriptive statistics and compared them using standardized differences. ${ }^{50}$

We modelled in-hospital death, ICU admission and unplanned 30-day readmission using modified Poisson regression, ${ }^{51}$ which uses a robust error variance to estimate relative risks (RRs). We used negative binomial regression, which estimates rate ratios, to model length of hospital stay. Since age 
is a strong predictor of disability ${ }^{6}$ and adverse COVID-19 outcomes, ${ }^{3}$ we derived overall models and models in patients 64 years of age or younger and 65 years or older separately. We selected this age threshold because risk of death associated with COVID-19 is elevated in patients who are older than 65 years of age $^{3}$ and Ontario residents become eligible for Old Age Security pension and the Ontario Drug Benefit at this age. We created the following sequential models that were adjusted for confounders: age, sex and residence in long-term care, $;^{1-4,7-10}$ model 1 variables and medical comorbidity, dementia and psychiatric disorders (although these are correlated with disability, ${ }^{10,43,44}$ we wanted to isolate risk associated with disability from that associated with chronic illness broadly); model 2 variables and predicted mortality risk using mAPACHE scores; and model 3 variables and neighbourhood-level income and visible minority quintiles (for overall models only, because these could accommodate more variables).

In additional analyses, we stratified overall models by sex; described overall outcomes by type of disability (physical only, hearing or vision only, traumatic brain injury, or intellectual or developmental only and multiple); re-ran overall models, including dementia, in our disability definition; and re-ran overall models while also controlling for the number of previous hospital admissions over the study period. We performed all analyses using R version 4.0.2 (https:// www.R-project.org/).

Table 1: Frequency of disability diagnoses by International Statistical Classification of Diseases and Related Health Problems, 10th revision (ICD-10-CA) codes

\section{Disability category}

ICD-10-CA code

Physical disability

Vision or hearing

impairment

Traumatic brain injury or intellectual or developmental disability

M05, M06
M15, M16, M17, M19
M45, M46
M50.00, M51.2, M51.3,
M86.4 M86.5, M86.6
M35.3, M47, M80
G20, G21
G23, G24.5, G24.9, G25
G35
G40
G62, G63
G72
G81
G82, G83
I69

S14.1, S24.1, S34.1, T91.3

$\mathrm{S} 32.4, \mathrm{~S} 32.5, \mathrm{~S} 32.7, \mathrm{~S} 32.8$

Z89.4, Z89.5, Z89.6, Z89.7, Z89.8

Z99.3, Z99.8

B91, G10, G11, G12, G31.8, G32.8, G55, G57, G70, G80, G90, G95

$\mathrm{H} 25, \mathrm{H} 26$

$\mathrm{H} 40, \mathrm{H} 42$

$\mathrm{H} 54$

E10.33, E11.33, H35, H36, H91.9

F79.8, F84.0, F84.8, F84.9, Q90.9

S02.1, S02.3, S02.7, S02.8, S06.2, S06.3, $\mathrm{S} 06.4$, S06.5, S06.6, S06.8, T90.5
No. (\%) of disability diagnoses $n=430$ *

$11(2.57)$

56 (13.08)

$10(2.34)$

$11(2.57)$

$8(1.87)$

7 (1.64)

27 (6.31)

$23(5.37)$

$9(2.10)$

17 (3.97)

14 (3.27)

$8(1.87)$

$23(5.37)$

15 (3.50)

$33(7.71)$

$7(1.64)$

Fracture of the vertebral column with spinal cord injury

Fracture of the lower back or pelvis

$11(2.57)$

Traumatic amputation of the lower limb

$11(2.57)$

Dependence on a wheelchair or other enabling

7 (1.64) machines or devices

Other neurologic disorders

Cataracts

Glaucoma

$10(2.34)$

Blindness and low vision

$6(1.40)$

Other sensory impairment

Intellectual or developmental disability

$6(1.40)$

Traumatic brain injury

*Because patients could have multiple disabilities there were 428 total disability diagnoses across 285 hospital admissions. 


\section{Ethics approval}

We obtained approval from the research ethics board at each participating site.

\section{Results}

Between Jan. 1 and Nov. 30, 2020, there were 1279 hospital admissions for COVID-19 at our sites. The median age of the patients was 66 (interquartile range [IQR] 54-79) years, 742 (58.0\%) were male and $285(22.3 \%)$ had a recorded disability. Among admissions for patients with a disability, 212 (74.4\%) had a physical disability, $18(6.3 \%)$ had a hearing or vision impairment, 24 (8.4\%) had a traumatic brain injury or intellectual or developmental disability and $31(10.9 \%)$ had multiple disabilities. We found that patients with a disability were older than those without a disability, were less likely to be male, and were more likely to be residents of long-term care facilities and have comorbidities (Table 2). Patients with disabilities also had higher baseline predicted risk of death (Appendix 1, Table S1, available at www.cmaj.ca/lookup/ doi/10.1503/cmaj.211277/tab-related-content).

\section{Table 2: Characteristics of patients with and without a disability who were admitted to hospital with COVID-19}

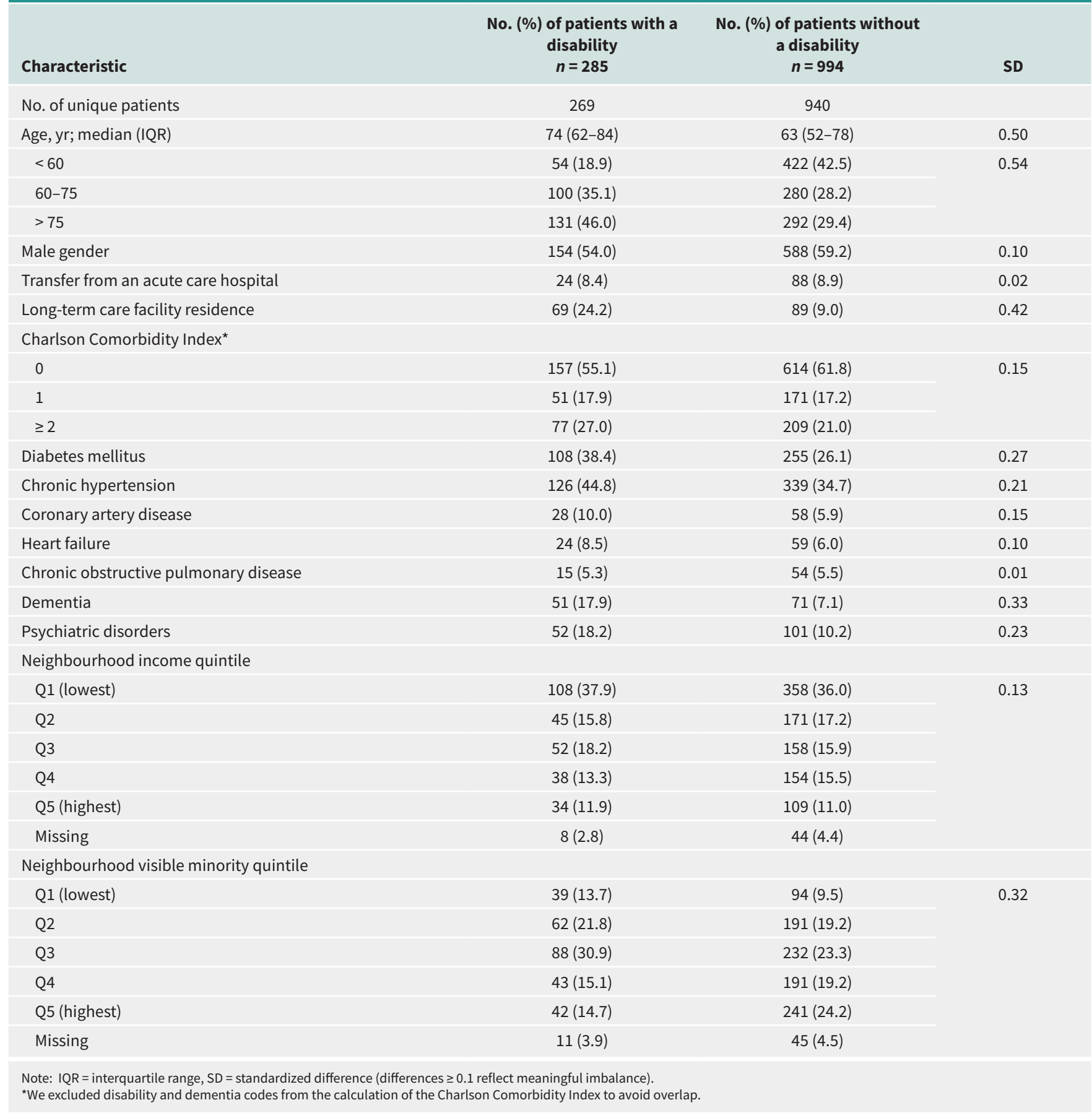




\section{Outcomes}

In unadjusted analyses, we found that patients with disabilities were more likely to die in hospital than those without disabilities (28.1\% v. 17.6\%; RR 1.57, 95\% confidence interval [CI] 1.19-2.06); the risk of death was not significantly different between those with and without disability after adjusting for age, sex, residence in a long-term care facility, medical comorbidity, dementia and psychiatric disorders (RR 1.09, 95\% Cl 0.82-1.45). After stratification by age, we found that adjusted risk was not significantly elevated in patients with disabilities aged 64 years or younger (RR 1.06, 95\% Cl 0.50-2.67) or in patients aged 65 years or older (RR 1.08, 95\% Cl 0.80-1.46) when compared with those without disabilities (Figure 1).

We found that admission rates to the ICU were lower in patients with disabilities than those without disabilities $(22.5 \% \mathrm{v}$. $28.3 \%$ ) but found no significant differences in rates after adjustment overall (RR $1.00,95 \% \mathrm{Cl} 0.75-1.33$ ) or after age stratification ( $\leq 64$ yr RR 1.00, 95\% Cl 0.66-1.52; $\geq 65$ yr RR $0.97,95 \%$ Cl 0.651.47) (Figure 2).

Patients with disabilities had longer hospital stays than those without disabilities (median 13.9 [IQR 5.8-30.1] d v. 7.8 [IQR 3.6$16.8] \mathrm{d}$; rate ratio $1.53,95 \% \mathrm{Cl} 1.34-1.75$ ), and this effect persisted after adjusting for age, sex, residence in a long-term care facility, medical comorbidity, dementia and psychiatric disorders (adjusted rate ratio $1.36,95 \% \mathrm{Cl} 1.19-1.56$ ). We determined that rate ratios for length of stay between patients with and without disabilities were greater in those aged 64 years or younger (rate ratio $1.47,95 \% \mathrm{Cl}$ $1.16-1.86$ ) and 65 years or older (rate ratio $1.31,95 \% \mathrm{Cl} 1.11-1.54$ ).
We found no differences in these results after further adjustment for predicted risk of death at admission (Figure 3).

Patients with disabilities were more likely to have unplanned 30-day readmissions than those without disabilities (17.6\% v. 7.9\%; RR 2.03, 95\% Cl 1.32-3.12), with the risk remaining elevated after we adjusted for age, sex, long-term care facility residence, medical comorbidity, dementia and psychiatric disorders (RR $1.77,95 \% \mathrm{Cl}$ 1.14-2.75). After stratification by age, we found that the risk of unplanned 30-day admissions was greater in patients with disabilities than those without disabilities who were 64 years of age or younger (RR 2.85, 95\% Cl 1.51-5.35) but not in those who were 65 years of age or older (RR 1.02, 95\% Cl 0.54-1.93). We found no differences in these results after further adjustment for predicted risk of death at admission (Figure 4).

In sex-stratified analyses, unplanned readmission risk was higher among males with disabilities than males without disabilities (RR 1.78, 95\% Cl 1.02-3.08), but this difference was not observed among females. Results for other outcomes were consistent when analyzing both males and females separately (Appendix 1, Table S2 and Table S3). Hospital stays were longer among both males and females with disabilities than those without disabilities (Appendix 1, Table S3). Outcomes by type of disability showed highest risks for poor outcomes among patients with traumatic brain injury or intellectual or developmental disabilities, or multiple disabilities (Appendix 1, Table S4). We found no changes after we included dementia in our disability definition (Appendix 1, Table S5 and Table S6) and after controlling for number of previous hospital admissions (Appendix 1, Table S7).

\begin{tabular}{|c|c|c|c|}
\hline Age, yr & Exposure & $\begin{array}{c}\text { No. (\%) with } \\
\text { outcome }\end{array}$ & RR $(95 \% \mathrm{Cl})$ \\
\hline 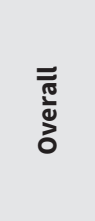 & $\begin{array}{l}\text { No disability } \\
\text { Disability: Unadjusted } \\
\text { Disability: Model } 1 \text { adjusted } \\
\text { Disability: Model } 2 \text { adjusted } \\
\text { Disability: Model } 3 \text { adjusted } \\
\text { Disability: Model } 4 \text { adjusted }\end{array}$ & $\begin{array}{c}175(17.6) \\
80(28.1)\end{array}$ & $\begin{array}{c}1.00 \text { (referent) } \\
1.57(1.19-2.06) \\
1.11(0.84-1.47) \\
1.09(0.82-1.45) \\
1.03(0.78-1.37) \\
1.03(0.78-1.37)\end{array}$ \\
\hline $\begin{array}{l}\text { G } \\
\text { VI }\end{array}$ & $\begin{array}{l}\text { No disability } \\
\text { Disability: Unadjusted } \\
\text { Disability: Model } 1 \text { adjusted } \\
\text { Disability: Model } 2 \text { adjusted } \\
\text { Disability: Model } 3 \text { adjusted }\end{array}$ & $\begin{array}{c}35(6.8) \\
10(12.0)\end{array}$ & $\begin{array}{c}1.00 \text { (referent) } \\
1.31(0.64-2.69) \\
1.10(0.52-2.32) \\
1.06(0.50-2.67) \\
1.22(0.57-2.64)\end{array}$ \\
\hline $\begin{array}{l}\qquad 0 \\
6 \\
\Lambda 1\end{array}$ & $\begin{array}{l}\text { No disability } \\
\text { Disability: Unadjusted } \\
\text { Disability: Model } 1 \text { adjusted } \\
\text { Disability: Model } 2 \text { adjusted } \\
\text { Disability: Model } 3 \text { adjusted }\end{array}$ & $\begin{array}{c}140(29.0) \\
70(34.7)\end{array}$ & $\begin{array}{c}1.00 \text { (referent) } \\
1.23(0.91-1.65) \\
1.09(0.81-1.48) \\
1.08(0.80-1.46) \\
1.01(0.75-1.37)\end{array}$ \\
\hline
\end{tabular}

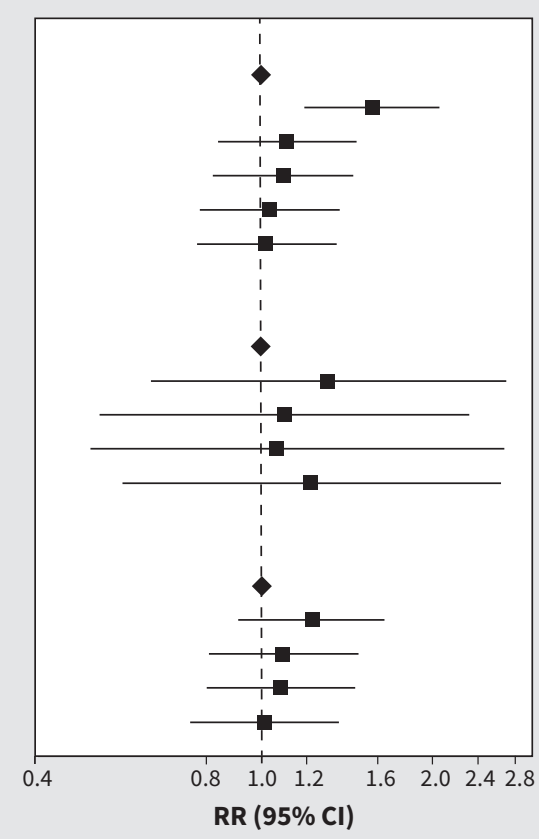

Figure 1: Risk of death among patients with and without a disability who were admitted to hospital with COVID-19. We adjusted all models for hospital site as a fixed effect. Model 1 was further adjusted for age, sex and residence in a long-term care facility. Model 2 was further adjusted for medical comorbidity, dementia and psychiatric disorders. Model 3 was further adjusted for predicted risk of death at presentation to hospital. Model 4 was further adjusted for neighbourhood-level income and proportions of patients who identified as a visible minority. Note: $\mathrm{Cl}=$ confidence interval, $\mathrm{RR}=$ relative risk. 


\begin{tabular}{|c|c|c|c|}
\hline Age, yr & Exposure & $\begin{array}{c}\text { No. (\%) with } \\
\text { outcome }\end{array}$ & RR $(95 \% \mathrm{Cl})$ \\
\hline $\begin{array}{l}\bar{\pi} \\
\frac{\pi}{0} \\
0\end{array}$ & $\begin{array}{l}\text { No disability } \\
\text { Disability: Unadjusted } \\
\text { Disability: Model } 1 \text { adjusted } \\
\text { Disability: Model } 2 \text { adjusted } \\
\text { Disability: Model } 3 \text { adjusted } \\
\text { Disability: Model } 4 \text { adjusted }\end{array}$ & $\begin{array}{c}281(28.3) \\
64(22.5)\end{array}$ & $\begin{array}{l}1.00 \text { (referent) } \\
0.81(0.61-1.07) \\
0.97(0.73-1.29) \\
1.00(0.75-1.33) \\
1.00(0.75-1.33) \\
1.00(0.75-1.33)\end{array}$ \\
\hline $\begin{array}{l}\text { छ } \\
\text { vi }\end{array}$ & $\begin{array}{l}\text { No disability } \\
\text { Disability: Unadjusted } \\
\text { Disability: Model } 1 \text { adjusted } \\
\text { Disability: Model } 2 \text { adjusted } \\
\text { Disability: Model } 3 \text { adjusted }\end{array}$ & $\begin{array}{c}185(36.1) \\
30(36.1)\end{array}$ & $\begin{array}{c}1.00 \text { (referent) } \\
0.98(0.66-1.45) \\
0.98(0.66-1.48) \\
1.00(0.66-1.52) \\
1.01(0.67-1.53)\end{array}$ \\
\hline $\begin{array}{l}\qquad 0 \\
6 \\
\Lambda 1\end{array}$ & $\begin{array}{l}\text { No disability } \\
\text { Disability: Unadjusted } \\
\text { Disability: Model } 1 \text { adjusted } \\
\text { Disability: Model } 2 \text { adjusted } \\
\text { Disability: Model } 3 \text { adjusted }\end{array}$ & $\begin{array}{l}96(19.9) \\
34(16.8)\end{array}$ & $\begin{array}{c}1.00 \text { (referent) } \\
0.86(0.58-1.28) \\
0.95(0.63-1.42) \\
0.97(0.65-1.47) \\
0.95(0.63-1.44)\end{array}$ \\
\hline
\end{tabular}

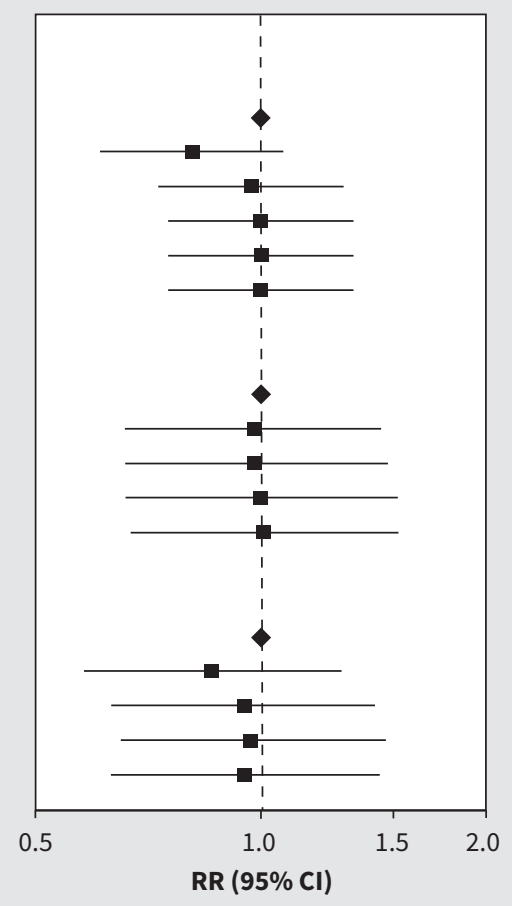

Figure 2: Risk of admission to the intensive care unit among patients with and without a disability who were admitted to hospital with COVID-19. We adjusted all models for hospital site as a fixed effect. Model 1 was further adjusted for age, sex and residence in a long-term care facility. Model 2 was further adjusted for medical comorbidity, dementia and psychiatric disorders. Model 3 was further adjusted for predicted risk of death at presentation to hospital. Model 4 was further adjusted for neighbourhood-level income and proportions of patients who identified as a visible minority. Note: $\mathrm{Cl}=$ confidence interval, $\mathrm{RR}=$ relative risk .

\section{Interpretation}

We found that patients with disabilities who were admitted to hospital with COVID-19 had longer hospital stays and an elevated risk of unplanned 30-day readmission than patients without disabilities. These risks were not explained by sociodemographic factors, comorbidities or illness severity at baseline, although patients with disabilities had a greater predicted risk of death. The greater risk of 30-day readmission for patients with disabilities was mainly driven by patients younger than 65 years of age. Although we found no significant differences in hospital deaths or ICU admission after adjustment, it should be noted that the confidence intervals are wide and do not preclude a meaningful increase in risk that might be detected in a larger sample. Our findings suggest disability-related needs should be included in plans for COVID-19 response, in particular to support patients in hospital and to plan postdischarge supports, incuding community supports, to reduce risk of readmission to hospital.

Several population-based studies have evaluated COVID-19 mortality in people with disabilities..$^{13,18-26} \mathrm{An}$ ecological study conducted in the United States showed that counties with a higher prevalence of disability had higher mortality rates, ${ }^{18}$ and a retrospective cohort study in England that used census and mortality data reported that people with disabilities made up $58 \%$ of deaths..$^{19} \mathrm{~A} 2020$ retrospective study involving 576 patients with neurologic disabilities reported higher case-fatality rates, ${ }^{13}$ as did studies in the United Kingdom ${ }^{20-23}$ and $\mathrm{US}^{24-26}$ that involved patients with intellectual or developmental disabilities. We found no elevated risk of death in patients with disabilities in our cohort after adjustment. This difference from previous studies could be due to our adjustment for a wider range of covariates. ${ }^{18,22-26}$ Most of these studies evaluated overall risk of death rather than in patients admitted to hospital. ${ }^{18-25}$ Our sample population of patients in hospital, which was dominated by older, less healthy people, had a higher baseline mortality risk, making it less likely to detect differences between patients with and without disabilities. A 2020 study conducted in the US showed that disparities in case-fatality rates were larger in young patients with disabilities compared with those without intellectual or developmental disabilities. ${ }^{26}$ This is similar to our finding that disparities in unplanned readmission were more pronounced in younger patients. Our findings are also consistent with data obtained for other conditions (e.g., pneumonia) that showed that patients with disabilities were at elevated risk for poor outcomes. ${ }^{52,53}$ Our data show that disability, along with older age and medical comorbidities - also known risk factors for poor outcomes among patients with other acute conditions ${ }^{54}-$ should be a priority target for support strategies for COVID-19.

We expected worse COVID-19 outcomes in patients with disabilities given higher rates of comorbidity, ${ }_{10}^{10}$ physiologic changes related to some disabilities, ${ }^{11,13}$ and the correlation between age and disability.., 6 Longer hospital stays and higher risk of readmission among patients with disabilities may reflect slower recovery and increased vulnerability to recurrent illness because of physiologic differences. ${ }^{11-13}$ 


\begin{tabular}{|c|c|c|c|}
\hline Age, yr & Exposure & $\begin{array}{l}\text { Median days } \\
\text { (IQR) }\end{array}$ & $\begin{array}{c}\text { Rate ratio } \\
(95 \% \mathrm{Cl})\end{array}$ \\
\hline \multirow{6}{*}{$\begin{array}{l}\overline{\text { సँ }} \\
\text { ठँ } \\
\text { ठ }\end{array}$} & No disability & $7.8(3.6-16.8)$ & 1.00 (referent) \\
\hline & Disability: Unadjusted & $13.9(5.8-30.1)$ & $1.53(1.34-1.75)$ \\
\hline & Disability: Model 1 adjusted & & $1.41(1.23-1.61)$ \\
\hline & Disability: Model 2 adjusted & & $1.36(1.19-1.56)$ \\
\hline & Disability: Model 3 adjusted & & $1.37(1.19-1.57)$ \\
\hline & Disability: Model 4 adjusted & & $1.39(1.22-1.60)$ \\
\hline \multirow{5}{*}{$\begin{array}{l}\text { \& } \\
\text { vi }\end{array}$} & No disability & $6.5(2.9-13.8)$ & 1.00 (referent) \\
\hline & Disability: Unadjusted & $11.8(4.6-28.0)$ & $1.69(1.33-2.14)$ \\
\hline & Disability: Model 1 adjusted & & $1.50(1.18-1.90)$ \\
\hline & Disability: Model 2 adjusted & & $1.47(1.16-1.86)$ \\
\hline & Disability: Model 3 adjusted & & $1.50(1.19-1.90)$ \\
\hline \multirow{5}{*}{$\begin{array}{l}\qquad 0 \\
01\end{array}$} & No disability & $10.5(4.3-21.3)$ & 1.00 (referent) \\
\hline & Disability: Unadjusted & $14.9(6.5-30.2)$ & $1.37(1.16-1.61)$ \\
\hline & Disability: Model 1 adjusted & & $1.35(1.14-1.59)$ \\
\hline & Disability: Model 2 adjusted & & $1.31(1.11-1.54)$ \\
\hline & Disability: Model 3 adjusted & & $1.33(1.13-1.57)$ \\
\hline
\end{tabular}

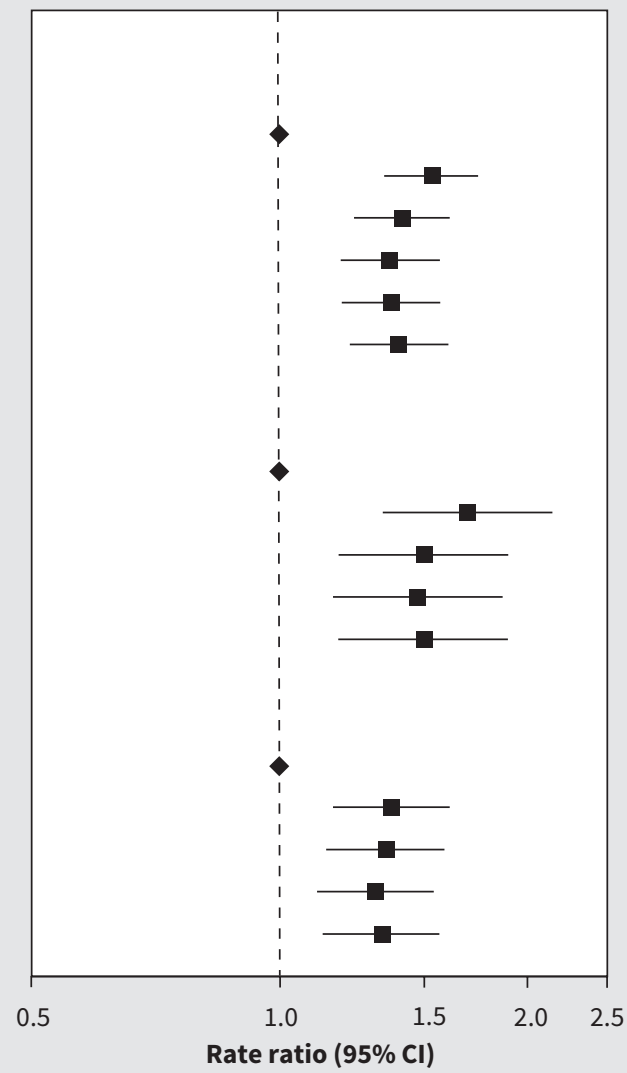

Figure 3: Length of hospital stay among patients with and without a disability who were admitted to hospital with COVID-19. We adjusted all models for hospital site as a fixed effect. Model 1 was further adjusted for age, sex and residence in a long-term care facility. Model 2 was further adjusted for medical comorbidity, dementia and psychiatric disorders. Model 3 was further adjusted for predicted risk of death at presentation to hospital. Model 4 was further adjusted for neighbourhood-level income and proportions of patients who identified as a visible minority. Note: $\mathrm{Cl}=$ confidence interval , IQR=interquartile range.

Studies should evaluate whether disparities reflect gaps in high-quality care for patients with disabilities. For example, communication failures contribute to patient harm,,$^{5,56}$ and pandemic conditions may have hindered communication more for patients with disabilities. Hospitals had restricted visitor policies that limited access for support persons who would ordinarily assist with communication. ${ }^{15}$ Facemasks and face shields also impede communication and may have a greater impact on people with disabilities. ${ }^{15}$ Pandemic restrictions have also affected access to outpatient clinical, interprofessional, personal care, meal and medication services for people with disabilities. ${ }^{57,58}$ These disruptions have had a profound impact on the physical, mental and social well-being of people with disabilities, ${ }^{59,60}$ and may contribute to readmission risk. The differential impact of disability at younger ages is notable. In younger groups, persons without a disability have higher baseline functioning, which results in a greater detectable difference in risk for poor outcomes. ${ }^{26}$ In older groups, differences between those with and without disabilities may be less pronounced because of greater comorbidity, frailty and physiologic changes related to aging at baseline. ${ }^{26}$

Our findings underscore the importance of prioritizing people with disabilities for COVID-19 vaccination. Vaccination is critical for preventing COVID-19 infection, admission to hospital and adverse clinical outcomes among patients with disabilities admitted to hospital. People with disabilities continue to experience barriers to vaccination access. ${ }^{61}$ Some groups of patients with disabilities, however, are at heightened risk for COVID-19 breakthrough infections and for adverse outcomes including hospital admission and death, even after being fully vaccinated. ${ }^{62}$

\section{Limitations}

Because our data were abstracted from 7 large urban or suburban hospitals, our findings may not be generalizable to other settings. However, our previous research ${ }^{27,28}$ showed that our cohort is similar to cohorts in studies conducted in the US and UK, ${ }^{63,64}$ and our data represent nearly $25 \%$ of contemporaneous COVID19 hospital admissions in Ontario. ${ }^{27} \mathrm{~A}$ strength of our study is that we were able to identify disability from 11 years of data rather than in the index hospital record only. ${ }^{65}$ However, we were limited to a medical model of disability that relies on diagnoses rather than self-reported disability. We may have missed patients with undiagnosed disabilities or whose disabilities were not recorded for a hospital admission in a general medical service at one of the participating hospitals. However, any misclassification of patients with disabilities as not having a disability would likely result in underestimation of the risks, which means that the 


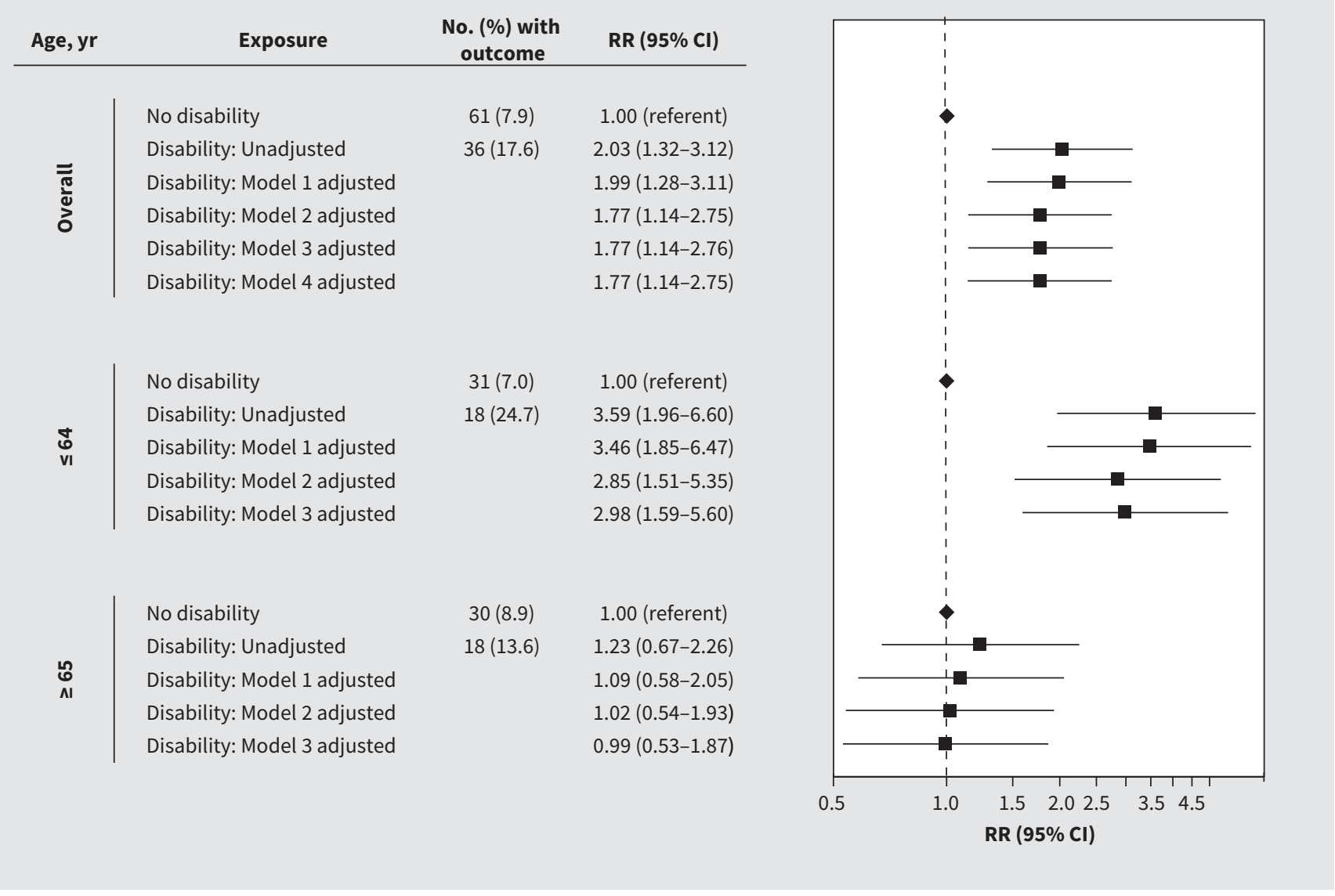

Figure 4: Risk of unplanned 30-day readmission to hospital among patients with and without a disability who were admitted to hospital with COVID-19. We adjusted all models for hospital site as a fixed effect. Model 1 was further adjusted for age, sex and residence in a long-term care facility. Model 2 was further adjusted for medical comorbidity, dementia and psychiatric disorders. Model 3 was further adjusted for predicted risk of death at presentation. Model 4 was further adjusted for neighbourhood-level income and proportions of patients who identified as a visible minority. Note: $\mathrm{Cl}=$ confidence interval, $\mathrm{RR}=$ relative risk.

results reported herein are conservative. On the other hand, disability-related diagnoses vary in their impact on each person. ${ }^{65}$ This issue relates to the intersection of disability with chronic illness, some of which reflects aging. ${ }^{43}$ However, we stratified models by age and adjusted for comorbidity.

Our sample size was not sufficient to evaluate outcomes in patients with specific disabilities separately beyond descriptive analyses. We were also unable to include all covariates at once in the age-stratified multivariable models, given the smaller sample sizes available for these analyses. There may be a risk of type 1 error, given the number of comparisons. Although we adjusted for the most important predictors of poor outcomes for COVID-19, ${ }^{66}$ we did not have data on obesity or smoking, which are more common in people with disabilities, ${ }^{67}$ and income and ethnicity were measurable only at the neighbourhood level. We were able to capture readmissions only to GEMINI hospitals; however, more than $80 \%$ of readmissions in our region go to the original hospital of admission. ${ }^{68}$ We may have missed some patients with COVID-19 who were admitted to hospital for nonmedical reasons and were not cared for by a medical service or in an ICU, but the number of patients is likely small. Finally, the COVID-19 pandemic and response continue to rapidly evolve; our data reflect experiences during the first
2 major waves of the pandemic in Ontario, but the nature of the observed disparities may change as the pandemic progresses.

\section{Conclusion}

Our findings highlight the importance of a pandemic response that prioritizes the needs of patients with disabilities who have COVID19 , particularly when they are in hospital and after their hospital stay. For patients with sensory, intellectual or developmental disabilities especially, accommodations should be prioritized for those requiring support persons to assist with communication. Training for clinicians about the needs and rights of people with disabilities may also be useful. Higher unplanned readmission rates underscore the importance of a patient-oriented discharge process that helps patients plan how to manage at home with safe options for assistance with personal care. Our findings also show the need to include disability-related data in COVID-19 surveillance to track outcomes of COVID-19 prevention and intervention strategies. Future research should also evaluate the intersection of disability with gender, experiences of racism and other social determinants of health, which may further affect COVID-19 outcomes. Such efforts should be prioritized in the pandemic response to ensure equitable care for patients with disabilities who have COVID-19. 


\section{References}

1. Morciano M, Stokes J, Kontopantelis E, et al. Excess mortality for care home residents during the first 23 weeks of the COVID-19 pandemic in England: a national cohort study. BMC Med 2021;19:71.

2. Karmakar M, Lantz PM, Tipirneni R. Association of social and demographic factors with COVID-19 incidence and death rates in the US. JAMA Netw Open 2021;4:e2036462.

3. Yanez ND, Weiss NS, Romand JA, et al. COVID-19 mortality risk for older men and women. BMC Public Health 2020;20:1742.

4. Christensen DM, Strange JE, Gislason G, et al. Charlson Comorbidity Index score and risk of severe outcome and death in Danish COVID-19 patients. J Gen Intern Med 2020;35:2801-3.

5. World report on disability. Geneva: World Health Organization; 2011.

6. Disability in Canada: initial findings from the Canadian Survey on Disability. Ottawa: Statistics Canada; 2016.

7. Parish SL, Rose RA, Andrews ME. Income poverty and material hardship among US women with disabilities. Soc Serv Rev 2009;83:33-52.

8. Taylor DM. Americans with disabilities: 2014. Washington (D.C.): US Census Bureau; 2018.

9. National Center on Birth Defects and Developmental Disabilities, \& Division of Human Development and Disability. Disability and Health Data System (DHDS) data. Washington (D.C.): Centers for Disease Control and Prevention; 2019.

10. Dixon-Ibarra A, Horner-Johnson W. Disability status as an antecedent to chronic conditions: National Health Interview Survey, 2006-2012. Prev Chronic Dis 2014;11:130251.

11. Korupolu R, Stampas A, Gibbons C, et al. COVID-19: Screening and triage challenges in people with disability due to spinal cord injury. Spinal Cord Ser Cases 2020;6:35.

12. Galea MD, Gelman MA, Galea VP, et al. COVID-19 in spinal cord injury patients at a veterans administration hospital: a case series. J Spinal Cord Med 2021 Jan. 19 [Epub ahead of print];1-13. doi: 10.1080/10790268.2020.1871254.

13. Garcia-Axorin D, Martinez-Pias E, Trigo J, et al. Neurological comorbidity is a predictor of death in COVID-19 disease: a cohort study on 576 patients. Front Neurol 2020;11:781.

14. Armitage R, Bellums LA. The COVID-19 response must be disability inclusive. Lancet Public Health 2020;5:e257.

15. Boyle CA, Fox MH, Havercamp SM, et al. The public health response to the COVID-19 pandemic for people with disabilities. Disabil Health J 2020;13: 100943.

16. Kuper H, Banks LM, Bright T, et al. Disability-inclusive COVID-19 response: What it is, why it is important and what we can learn from the United Kingdom's response. Wellcome Open Res 2020;5:79.

17. Reed NS, Meeks LM, Swenor BK. Disability and COVID-19: who counts depends on who is counted. Lancet Public Health 220;5:e423.

18. Olulana O, Abedi V, Avula V, et al. Regional association of disability and SARSCoV-2 infection in 369 counties in the United States [preprint]. medRxiv 2020 June 26. doi: https://doi.org/10.1101/2020.06.24.20139212.

19. Bosworth ML, Ayoubkhani D, Nafilyan V, et al. Deaths involving COVID-19 by selfreported disability status during the first two waves of the COVID-19 pandemic in England: a retrospective, population-based cohort study. Lancet Public Health 2021;6:e817-e825.

20. Joy M, Hobbs FDR, Bernal JL, et al. Excess mortality in the first COVID pandemic peak: Cross-sectional analyses of the impact of age, sex, ethnicity, household size, and long-term conditions in people of known SARS-CoV-2 status in England. Br J Gen Pract 2020;70:e890-e898.

21. Huls A, Costa ACS, Dierssen M, et al. Medical vulnerability of individuals with Down syndrome to severe COVID-19 - data from the Trisomy 21 Research Society and the UK ISARIC4C survey. EClinicalMedicine 2021;33:100769.

22. Williamson EJ, McDonald HI, Bhaskaran K, et al. Risks of COVID-19 hospital admission and death for people with learning disability: population-based cohort study using the OpenSAFELY platform. BMJ 2021;374:n1592.

23. Baksh RA, Paper SE, Smith J, et al. Understanding inequalities in COVID-19 outcomes following hospital admission for people with intellectual disability compared to the general population: a matched cohort study in the UK. BMJ Open 2021;11:e052482.

24. Landes SD, Turk MA, Wong AWWA. COVID-19 outcomes among people with intellectual and developmental disability in California: the importance of type of residence and skilled nursing care needs. Disabil Health J 2021;14:101051.

25. Landes SD, Turk MA, Formica M, et al. COVID-19 outcomes among people with intellectual and developmental disability living in residential group homes in New York State. Disabil Health J 2020;13:100969.
26. Turk MA, Landes SD, Formica MK, et al. Intellectual and developmental disability and COVID-19 case-fatality trends: TriNetX analysis. Disabil Health $\mathrm{J}$ 2020;13:100942.

27. Verma AA, Hora $\mathrm{T}$, Young $\mathrm{H}$, et al. Characteristics and outcomes of hospital admissions for COVID-19 and influenza in the Toronto area. CMAJ 2021; 193:E410-8.

28. Verma AA, Guo Y, Kwan JL, et al. Patient characteristics, resource use and out comes associated with general internal medicine hospital care: the General Medicine Inpatient Initiative (GEMINI) retrospective cohort study. CMAJ Open 2017;5:E842-9.

29. Verma AA, Pasricha SV, Jung HY, et al. Assessing the quality of clinical and administrative data extracted from hospitals: the General Medicine Inpatient Initiative (GEMINI) experience. J Am Med Inform Assoc 2021;28:578-87.

30. Canadian coding standards for Version 2018 ICD-10-CA and CCI - Addendum: pandemics and epidemics (COVID-19). Ottawa: Canadian Institute for Health Information; 2021. Available: www.cihi.ca/en/bulletin/icd-10-ca-coding-direction -for-suspected-covid-19-cases (accessed 2021 Dec. 21).

31. Kadri SS, Gundrum J, Warner S, et al. Uptake and accuracy of the diagnosis code for COVID-19 among US hospitalizations. JAMA 2020;324:2553-4.

32. Khoury AJ, Hall A, Andresen E, et al. The association between chronic disease and physical disability among female Medicaid beneficiaries 18-64 years of age. Disabil Health J 2013;6:141-8.

33. Mann JR, Zhou L, McKee M, et al. Children with hearing loss and increased risk of injury. Ann Fam Med 2007;5:528-33.

34. Javitt JC, Zhou Z, Willke RJ. Association between vision loss and higher medical care costs in Medicare beneficiaries costs are greater for those with progressive vision loss. Ophthalmology 2007;114:238-45.

35. Langlois JA, Rutland-Brown W, Thomas KE. Traumatic brain injury in the United States: Emergency department visits, hospitalizations, and deaths. Atlanta: Centers for Disease Control and Prevention; 2004.

36. Lin E, Balogh R, Cobigo V, et al. Using administrative health data to identify individuals with intellectual and developmental disabilities: a comparison of algorithms. J Intellect Disabil Res 2013;57:462-77.

37. Darney BG, Biel FM, Quigley BP, et al. Primary cesarean delivery patterns among women with physical, sensory, or intellectual disabilities. Womens Health Issues 2017;27:336-44.

38. International Classification of Functioning, Disability and Health (ICF). Geneva: World Health Organization; 2001.

39. Brown HK, Ray JG, Chen S, et al. Association of pre-existing disability and severe maternal morbidity or mortality in Ontario, Canada. JAMA Netw Open 2021;4:e2034993.

40. Bourke J, Wong K, Leonard H. Validation of intellectual disability coding through hospital morbidity records using an intellectual disability populationbased database in Western Australia. BMJ Open 2018;8:e019113.

41. Hariyanto TI, Putri C, Situmeang FV, et al. Dementia is a predictor for mortality outcome from coronavirus disease 2019 (COVID-19) infection. Eur Arch Psychiatry Clin Neurosci 2021;271:393-5.

42. Li L, Li F, Fortunati F, et al. Association of a prior psychiatric diagnosis with mortality among hospitalized patients with coronavirus disease 2019 (COVID19) infection. JAMA Netw Open 2020;3:e2023282.

43. Strydom A, Chan T, King M, et al. Incidence of dementia in older adults with intellectual disabilities. Res Rev Disabil 2013;34:1881-5.

44. Disability and secondary conditions. Washington (D.C.): US Department of Health and Human Services; 2000.

45. Healthcare Cost and Utilization Project (HCUP). Clinical Classifications Software Refined (CCSR). Rockville (MD): Agency for Healthcare Research and Quality; 2020. Available: www.hcup-us.ahrq.gov/toolssoftware/ccsr/ccs_ refined.jsp (accessed 2020 Dec. 10).

46. Quan H, Li B, Couris CM, et al. Updating and validating the Charlson Comorbidity Index and score for risk adjustment in hospital discharge abstracts using data from 6 countries. Am J Epidemiol 2011;173:676-82.

47. Measuring health inequalities: a toolkit - area-level equity stratifiers using PCCF and PCCF+. Ottawa: Canadian Institute for Health Information; 2018. Available: www.cihi.ca/sites/default/files/document/cphi-toolkit-area-level -measurement-pccf-2018-en-web.pdf (accessed 2021 Jan. 20).

48. Fortis S, O'Shea AMJ, Beck BF, et al. An automated computerized critical illness severity scoring system derived from APACHE III: modified APACHE. J Crit Care 2018;48:237-42

49. Knight SR, Ho A, Pius R, et al.; ISARIC4C investigators. Risk stratification of patients admitted to hospital with COVID-19 using the ISARIC WHO Clinical Characterisation Protocol: development and validation of the $4 \mathrm{C}$ Mortality Score [published erratum in BMJ 2020;371:m4334]. BMJ 2020;370:m3339. 
50. Austin PC. Using the standardized difference to compare the prevalence of a binary variable between two groups in observational research. Commun Stat Simul Comput 2009;38:1228-34.

51. Zou G. A modified Poisson regression approach to prospective studies with binary data. Am J Epidemiol 2004;159:702-6.

52. Hirose N, Morita K, Jo T, et al. Differences in disease severity and in-hospital mortality in patients hospitalized for pneumonia with and without intellectual disabilities: a matched-pair retrospective cohort studying using nationwide in-patient database. J Intellect Dev Disabil 2021 Feb. 21. doi: 10.3109/13668250.2021.1877644.

53. McCoy JO, Holt M. Hospitalized adults with intellectual and developmental disabilities: confronting challenges. J Acute Care Phys Ther 2020;11:191-200.

54. Pawelka E, Karolyi M, Daller S, et al. Influenza virus infection: an approach to identifying predictors for in-hospital and 90-day mortality from patients in Vienna during the season 2017/18. Infection 2020;48:51-6.

55. Howard-Anderson J, Busuttil A, Lonowski S, et al. From discharge to readmission: Understanding the process from the patient perspective. J Hosp Med 2016;11:407-12.

56. Mitchell JP. Association of provider communication and discharge instructions on lower readmissions. J Healthc Qual 2015;37:33-40.

57. Negrini S, Donzelli S, Eng AN, et al. Feasibility and acceptability of telemedicine to substitute outpatient rehabilitation services in the COVID-19 emergency in Italy: an observational everyday clinical-life study. Arch Phys Med Rehabil 2020; 101:2027-32.

58. Steptoe A, Di Gessa G. Mental health and social interactions of older people with physical disabilities in England during the COVID-19 pandemic: a longitudinal cohort study. Lancet Public Health 2021;6:e365-73.

59. Jesus TS, Bhattacharjya S, Papadimitriou C, et al.; Refugee Empowerment Task Force, International Networking Group of the American Congress of Rehabilitation Medicine. Lockdown-related disparities experienced by people with disabilities during the first wave of the COVID-19 pandemic: scoping review and thematic synthesis. Int J Environ Res Public Health 2021;18:6178.
60. Embregts PJCM, Tournier T, Frielink N. Experiences and needs of direct support staff working with people with intellectual disabilities during the COVID19 pandemic: a thematic analysis. J Appl Res Intellect Disabil 2021;34:480-90.

61. Rotenberg S, Downer MB, Brown H, et al.; Ontario COVID-19 Science Advisory Table. COVID-19 vaccination for people with disabilities. Toronto: Ontario COVID-19 Science Advisory Table; 2021. Available: https://covid19-sciencetable.ca /wp-content/uploads/2021/06/COVID-19-Vaccination-for-People-with-Disabilities _v.1.1_20210615_published.pdf (accessed 2021 Nov. 29).

62. Hippisley-Cox J, Coupland CAC, Mehta N, et al. Risk prediction of COVID-19 related death and hospital admission in adults after COVID-19 vaccination: national prospective cohort study. BMJ 2021;374:n2244.

63. Richardson S, Hirsch JS, Narasimhan M, et al. Presenting characteristics, comorbidities, and outcomes among 5700 patients hospitalized with COVID-19 in the New York City area [published erratum in JAMA 2020;323:2098] JAMA 2020;323:2052-9.

64. Docherty AB, Harrison EM, Green CA, et al.; ISARIC4C investigators. Features of 20133 UK patients in hospital with COVID-19 using the ISARIC WHO Clinical Characterisation Protocol: prospective observational cohort study. BMJ 2020;369:m1985.

65. Brown HK, Carty A, Havercamp S, et al. Identifying reproductive-aged women with physical and sensory disabilities in administrative health data: a systematic review. Disabil Health J 2020;13:100909.

66. Dessie ZG, Zewotir T. Mortality-related risk factors for COVID-19: a systematic review and meta-analysis of 42 studies and 423117 patients. BMC Infect Dis 2021;21:855.

67. Krahn GL, Walker DK, Correa-De-Araujo R. Persons with disabilities as an unrecognized health disparity population. Am J Public Health 2015;105 (Suppl 2):S198-206.

68. Staples JA, Thiruchelvam D, Redelmeier DA. Site of hospital readmission and mortality: a population-based retrospective cohort study. CMAJ Open 2014;2:E77-85.
Competing interests: Amol Verma has received personal fees from Ontario Health, and personal grant funding from AMS Healthcare (Compassion and AI Fellowship) and St. Michael's Hospital. Michael Fralick is a consultant for Proof Diagnostics, a company that has created a point-of-care testing device using CRISPR for COVID-19. He has also received grants from the Canadian Institutes of Health Research (CIHR) and support from grants from the Canadian Military for clinical trials to identify treatments for COVID-19. Fahad Razak has received personal fees from Ontario Health and is a member of the Ontario COVID-19 Science Advisory Table. Yona Lunsky has received a grant from CIHR for research on disability and health during COVID-19. She is a member of the Board of Directors for Special Olympics Canada. Margaret Herridge has received grants from CIHR. No other competing interests were declared.

This article has been peer reviewed.

Affiliations: Department of Health and Society (Brown), University of Toronto Scarborough, Scarborough, Ont.; Li Ka Shing Knowledge Institute (Saha, Chan, Razak, Verma), St. Michael's Hospital; Dalla Lana School of Public Health (Brown, Rosella), Departments of Mechanical and Industrial Engineering (Chan), Medicine (Cheung, Fralick, Herridge, Kwan, Rawal, Tang, Weinerman, Razak, Verma), Computer Science (Ghassemi) and Psychiatry (Lunsky), University of Toronto; Department of Medicine (Cheung, Fralick, Rawal), Sinai Health System; Vector Institute (Ghassemi), Toronto General Hospital; Department of Medicine (Herridge, Cheung), University Health Network; Department of Medicine (Weinerman), Sunnybrook Health Sciences Centre; Azrieli Adult Neurodevelopmental Centre (Lunsky), Centre for Addiction \& Mental Health; Department of Medicine (Razak, Verma), Unity Health Toronto, Toronto, Ont.; Institute for Better Health (Rosella, Tang), Trillium Health Partners, Mississauga, Ont.

Contributors: Yona Lunsky, Fahad Razak and Amol Verma were joint senior authors. This study was conceived by all of the authors and designed by Hilary Brown, Amol Verma, Fahad Razak and Yona Lunsky, with substantial input from all of the authors. Amol Verma, Michael
Fralick, Janice Kwan, Adina Weinerman, Terence Tang and Fahad Razak contributed to data collection. Sudipta Saha conducted the data analysis. Hilary Brown and Amol Verma wrote the first draft of the manuscript. All of the authors contributed to the interpretation of the results, critically revised the manuscript for important intellectual content, gave final approval of the version to be published and agreed to be accountable for all aspects of the work.

Content licence: This is an Open Access article distributed in accordance with the terms of the Creative Commons Attribution (CC BY-NC-ND 4.0) licence, which permits use, distribution and reproduction in any medium, provided that the original publication is properly cited, the use is noncommercial (i.e., research or educational use), and no modifications or adaptations are made. See: https://creativecommons.org/licenses/ by-nc-nd/4.0/

Funding: This study was supported by Canadian Institutes of Health Research (CIHR) Grant VR4-172743. The development of the GEMINI data platform was supported with funding from the Canadian Cancer Society, the Canadian Frailty Network, the CIHR, the Canadian Medical Protective Association, Green Shield Canada Foundation, the Natural Sciences and Engineering Research Council of Canada, Ontario Health, the St. Michael's Hospital Association Innovation Fund and the Department of Medicine at the University of Toronto, with in-kind support from partner hospitals and the Vector Institute. The funding source had no role in the design or conduct of the study; collection, management, analysis, or interpretation of the data; preparation, review, or approval of the manuscript; or decision to submit the manuscript for publication.

Data sharing: Data from this manuscript can be accessed upon request to the corresponding author, to the extent that is possible in compliance with local research ethics board requirements and data-sharing agreements.

Accepted: Dec. 3, 2021

Correspondence to: Amol Verma, amol.verma@mail.utoronto.ca 